


\title{
A NOVEL SYNTHESIS OF FUSED ISOTHIAZOLE RING SYSTEMS
}

\author{
ANTONELLA CAPPERUCCI ${ }^{a}$, ALESSANDRO DEGL'INNOCENTI*b, MARIA \\ FUNICELLO ${ }^{b}$, PATRIZIA SCAFATO $b$, PIERO SPAGNOLO*C \\ a Dipartimento di Chimica Organica, via G. Capponi 9,50121 Firenze. \\ bDipartimento di Chimica, Università della Basilicata, via N. Sauro 85, 85100 Potenza. \\ cDipartimento di Chimica "A.Mangini", viale Risorgimento, 4, 40100 Bologna.
}

Abstract The reaction of aromatic and heteroaromatic aldehydes with bis(trimethylsilyl)sulfide leads to the corresponding thioaldehydes, which, through a fine tuning of the reaction conditions, are trapped both intermolecularly and intramolecularly, thus disclosing a novel methodology for the synthesis of fused isothiazole ring systems.

Increasing interest has recently been devoted to the synthesis and the reactivity of thiocarbonyl compounds. ${ }^{1}$ The generally high reactivity of such compounds, which are versatile intermediates in organic synthesis, has hampered their investigation and, to date, substantial work has been made toward the development of novel methodologies for their synthesis and synthetic applications.

In this context, particularly attracting appear to be thioaldehydes, ${ }^{2}$ that have been shown to be extremely reactive intermediates in the synthesis of complex natural products.

Our joint interest in the chemistry of thiocarbonyl ${ }^{3}$ and azido compounds ${ }^{4}$ very recently led us to undertake a chemical investigation of previously unknown aromatic and heteroaromatic $Q$-azidocarbothioaldehydes.

The thermolysis of aryl and heteroaryl azides bearing $\alpha, \beta$-unsaturated orthosubstituents represents a known convenient route to the synthesis of various fused azoles. ${ }^{4}$ Only one report is available in the literature concerning intramolecular cyclizations of azides onto an adjacent thiocarbonyl substituent. In fact, $Q$-azidobenzophenone and -acetophenone have been shown to undergo spontaneous decomposition at room temperature to furnish 3-phenyl- and 3-methyl-2,1benzisothiazole in fairly good yield. ${ }^{5}$ However, an extension of the same type of reaction to aromatic and heteroaromatic $\mathbf{Q}$-azidothioaldehydes does not appear to have been attempted so far.

We report in this communication that the reaction of aromatic and five-membered heteroaromatic $\underline{0}$-azidoaldehydes with bis(trimethylsilyl)sulfide (HMDST) can smoothly afford elusive $\Omega$-azidothioaldehydes which can be led to fused isothiazoles or Diels-Alder thioaldehyde-diene adducts through a fine tuning of the reaction conditions. 
In fact, when $Q$-azidoaldehydes are reacted with HMDST in the presence of $\mathrm{CoCl}_{2} \cdot 6 \mathrm{H}_{2} \mathrm{O}$ and an appropriate diene, the transient thioaldehydes are isolated as DielsAlder cycloadducts, in satisfactory yields as a result of their intermolecular trapping by the diene. The mildness of the reaction conditions can allow the survival of the azido function, that is thence prone to further synthetic elaboration. On the other hand, when Q-azidoaldehydes are reacted with HMDST in the presence of a stronger catalyst such as<smiles>CC1=C(C)CC(c2ccccc2N)SC1</smiles>

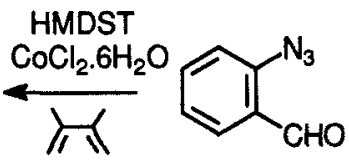
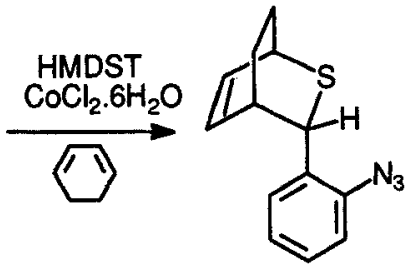

HMDST<smiles></smiles><smiles>C=C(CC)C(=C)CC(=O)OCCOC</smiles><smiles></smiles>
$X=0, S$.

$\mathrm{HCl}$ (and in the absence of diene) the azido group itself can act as efficient thioaldehyde trapper, thus offering a novel practicable route to fused isothiazole ring systems.<smiles></smiles>

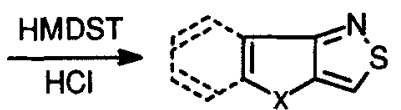

$$
X=0, S \text {. }
$$<smiles></smiles>

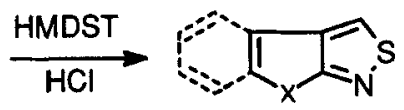

A further point of interest stems from today's ready availability of $\underline{\mathrm{Q}}$-azido carbaldehydes derived from five-membered heteroaryl systems, including inter alia, furan, benzofuran, thiophene, benzothiophene, and indole.

In conclusion, the reaction of $\Omega$-azido aldehydes with bis(trimethylsilyl)sulfide can smoothly result in the formation of $Q$-azidothioaldehydes, which represent a new class of synthetically appealing thioaldehydes.

\section{REFERENCES}

1.Metzner, P. Synthesis 1992, 1185; McGregor, W.M.; Sherrington, D.C. Chem. Soc. Rev. 1993, 199.

2. Vedejs, E.; Wittemberger, S.J..J. Am. Chem.Soc. 1990, 112, 4357 and refs. cited therein.

3.Capperucci, A.; Degl'Innocenti, A.; Ricci, A.; Mordini, A.; Reginato, G. J. Org. Chem., 1991, $56,7323$.

4. Funicello, M.; Spagnolo, P.; Zanirato, P. Acta Chem. Scand. 1993, 47, 231.

5.Ashby, J.; Suschitsky H. Tetrahedron Lett., 1971, 1315. 